\title{
Para sport translation of the IOC consensus on recording and reporting of data for injury and illness in sport
}

\author{
Wayne Derman (D) , 1,2,3 Marelise Badenhorst (D) , 1,2,4 Cheri Blauwet, 3,5 \\ Carolyn A Emery (D) ${ }^{6,7}$ Kristina Fagher (D) , ${ }^{8}$ Young-Hee Lee, ${ }^{9,10,11}$ James Kissick, ${ }^{3,12}$ \\ Jan Lexell, ${ }^{3,8,13}$ Ian Stuart Miller (D) , ${ }^{14,15}$ Babette M Pluim (D) , $16,17,18$ \\ Martin Schwellnus (D) , ${ }^{2,19}$ Kathrin Steffen (D) , 20,21,22 Peter Van de Vliet, ${ }^{23,24}$ \\ Nick Webborn, ${ }^{3,25,26}$ Richard Weiler (D) ${ }^{17,27}$
}

\begin{abstract}
- Additional supplemental material is published online only. To view, please visit the journal online (http://dx.doi. org/10.1136/bjsports-2020103464).
\end{abstract}

For numbered affiliations see end of article.

\section{Correspondence to}

Professor Wayne Derman, Institute of Sport and Exercise Medicine, Division of Orthopaedic Surgery, Department of Surgical Sciences, Stellenbosch University Faculty of Medicine and Health Sciences, Cape Town, South Africa; ewderman@iafrica.com

Accepted 31 March 2021 Published Online First 14 April 2021

\section{ABSTRACT}

In 2020, the IOC proposed a universal methodology for the recording and reporting of data for injury and illness in sport. Para sport is played by individuals with impairment, and they have a unique set of considerations not captured by these recommendations. Therefore, the aim of this addendum to $\mathrm{IOC}$ consensus statement was to guide the Para sport researcher through the complexities and nuances that should be taken into consideration when collecting, registering, reporting and interpreting data regarding Para athlete health. To develop this translation, experts in the field of Para sports medicine and epidemiology conducted a formal consensus development process, which began in March 2020 with the formation of a consensus group that worked over eight phases, incorporating three virtual consensus meetings to finalise the translation. This translation is consistent with the IOC consensus statement, yet provides more detailed Para athlete specific definitions and recommendations on study population, specifically, diagnostic and eligible impairment categorisation and recording of adaptive equipment, and defining and classifying health problems in the context of Para sport. Additionally, recommendations and Para athlete specific examples are described with regards to injury mechanism, mode of onset, injury and illness classification, duration, capturing and reporting exposure and risk. Finally, methods and considerations are provided to cater to the varied needs of athletes with impairment with respect to data collection tools. This harmonisation will allow the science to develop and facilitate a more accurate understanding of injury and illness patterns for tailoring evidenceinformed prevention programmes and enabling better planning of medical services for Para sport events.

\section{INTRODUCTION}

In keeping with the increased popularity in Para sport over the past several decades, the number of publications regarding injury and illness in this population of athletes has increased significantly. ${ }^{1-4}$ Data from studies during this period have indicated that in many sport settings, rates of injury and illness are higher in Paralympic athletes than in their Olympic counterparts. ${ }^{5-14}$ Therefore, injury and illness prevention programmes are of importance.
The collection and reporting of accurate health data constitutes the first step in this process and has been identified as a target for improvement in the Para sport setting. $^{12} 15$

To gain consistency in definitions, collection and subsequent reporting of injury and illness data, the IOC produced a consensus statement early in 2020, ${ }^{16}$ with several follow-up papers to detail sport specific nuances in data collection and reporting (tennis translation ${ }^{17}$; golf translation $^{18}$ ). The translation of the IOC consensus statement guides the Para sport researcher through the complexities of describing athlete impairment types, classifications and the health problems associated with sport participation. This harmonisation will allow the science to develop and facilitate a more accurate understanding of injury and illness patterns for tailoring evidence-informed prevention programmes and enabling better planning of medical services for Para sport events.

\section{METHODS}

This translation was developed after the publication of the IOC consensus statement. ${ }^{16}$ This task was initiated by WD, who acted as chairperson of the consensus group. An initial group was selected from the medical committee of the International Paralympic Committee (IPC) and IPC Management Team (WD, CB, JK, JL, PVV, NW), who are academically experienced in Para sport epidemiology. This group was expanded to include authors from the IOC consensus statement (CE, BMP, MS) and additional authors with experience in this field (MB, KF, Y-HL, ISM, KS, RW)(online supplemental appendix 1). A formal consensus development process was conducted. This process was modified (online only), due to travel restrictions associated with the novel COVID-19 pandemic.

This process was conducted over nine phases: (1) initial discussions and selection of consensus group; (2) assignment of designated topic areas to seven working groups; (3) review of available literature and drafting of proposed definitions, recommendations and Para sport specific examples by working groups; (4) circulation of a draft with all contributions; (5) a 2-day consensus meeting held on the 29-30 June 2020, during which all contributions were discussed section by section; (6) revision 
of drafts by working groups according to input received, and consensus reached during the meetings; (7) a final consensus meeting held on the 4 August 2020 to verify all changes; (8) final edits made by an editorial group (WD and MB); (9) review and approval of the final draft by all authors. In all instances, consensus was reached unanimously.

Throughout the document, unless otherwise stated, we are in accordance with the recommendations of the IOC consensus statement. However, certain definitions, parameters and examples that relate specifically to Para athletes must be highlighted. The current document has been specifically written to be read in parallel with the IOC consensus statement. The ordering of sections varies slightly given that defining the population of Para athletes is of critical importance and must be considered from the outset of any injury and illness surveillance work in this population.

\section{Terminology}

Some important terminology relating to Para sport must be understood. A Para atblete is the IPC's term for a sportsperson with an impairment. ${ }^{19-21}$ This term is used in this consensus statement as it applies to all athletes with an impairment partaking in sports that are recognised by the IPC. It is different from the term Paralympian or Paralympic athlete, which refers specifically to a Para athlete who has competed at a Paralympic Games. Para sport refers to sports that are played by individuals with impairment. Importantly, the term 'Para sport' should only be used to refer to sports that are recognised by the IPC, ${ }^{20}$ and includes competitors who are affected by one or more of the 10 eligible impairment types.

Other often confused definitions include the terms impairment, disability and wheelchair athlete. The World Health Organization (WHO), in their International Classification of Functioning, Disability and Health, defines impairment as 'any loss or abnormality of psychological, physiological or anatomical structure or function'. ${ }^{21}$ As defined by the WHO, disability is considered 'an umbrella term for impairments, activity limitations, and participation restrictions' (p3). ${ }^{22}$ The term 'wheelchair athlete' has been used by some authors, broadly meaning athlete with spinal cord injury, as historically this was the only impairment at the early Paralympic Games. In the overall research context, this is now unhelpful as athletes with many different impairments use wheelchairs for their sport or participate in sports without wheelchairs, for example, swimming or sailing, but require one for daily use. ${ }^{23}$ Instead, sport-specific and impairment specific terminology should be used.

\section{CONSENSUS RECOMMENDATIONS}

\section{Study population characteristics}

\section{Defining diagnostic and associated impairment categories}

As outlined in the IOC consensus statement, ${ }^{16}$ the athlete's impairment type and underlying diagnosis/medical condition must be considered as part of the minimum demographic information collected in Para sport injury and illness surveillance, given that the background diagnosis is often intrinsically related to injury and illness risk and is often poorly recorded or absent. ${ }^{24}$ For example, an athlete with a complete spinal cord injury who uses a wheelchair daily, is at heightened risk of shoulder injury, whereas an amputee athlete is at increased risk for skin injury or illness at the residual limb -socket interface. ${ }^{102425}$

It is important to note that there remains significant confusion in the sports medicine and research community regarding the difference between diagnosis, eligible impairment category and classification category (sport class). To be eligible to compete in Para sport, first, an athlete must have a diagnosis that could lead to an impairment. This impairment must be one of the 10 eligible impairment types as defined by the IPC classification code (impaired muscle power; impaired passive range of movement; limb deficiency; leg length difference; short stature; hypertonia; ataxia; athetosis; vision impairment and intellectual impairment). ${ }^{26}$ For purposes of promoting fair competition in Para sport, athletes are grouped into functional categories, or classifications, based on the classification rules of the Para sport Federation, which in turn need to align with the IPC classification code (eligible impairment). ${ }^{26}$ The aim of this classification is to determine how athletes should grouped for competition, based on the degree of activity limitation resulting from the impairment. Additionally, each Para sport code has classification rules which describe the process by which eligible athletes should be classified.

To determine injury and illness risk, one must identify the underlying diagnosis or pathophysiological process that leads to the eligible impairment (eg, cerebral palsy, which causes athetosis). Whenever possible, information regarding the athlete's diagnosis should be collected directly via the assessment of a licensed/registered clinician or via evaluation of a clinically verified medical record that allows for this to be confirmed, in preference to athlete or staff self-report.

Since its inception in 1948, the Paralympic movement expanded from a small competition involving only athletes with spinal cord injuries, to include athletes with many different underlying diagnoses. ${ }^{27}$ Although the range of potential diagnoses in Para sport is vast, for injury surveillance purposes, they must be grouped in a pragmatic way to be used in various global sport settings. This categorisation must be sufficiently specific to allow risk assessment and inform injury and illness prevention strategies. However, if diagnostic categories are divided into very detailed subcategories there is a risk that statistical power will be reduced, and the confidentiality of individuals may be compromised, particularly for those with a unique diagnosis (eg, rare genetic conditions). Figure 1 depicts the current consensus recommendation of how to define and record diagnostic categories for injury and illness surveillance in Para sport.

\section{Recording of adaptive equipment}

Many Para athletes use adaptive equipment in both their daily lives as well as for sports participation. Yet athletes with similar impairment types may or may not elect to use the same kind of adaptive equipment. For example, a unilateral below-knee amputee may either ambulate with a prosthesis or use a wheelchair for daily mobility. Given the intimate athlete-equipment interface and its potential to impact loading and biomechanics, this may have a significant impact on injury or illness risk and should be accounted for in surveillance programmes. Figure 2 depicts the minimum standard consensus recommendations of how to define and record adaptive equipment categories for injury and illness surveillance in Para sport. If an athlete reports using more than one type of adaptive equipment in daily life (eg, manual wheelchair and crutches), the equipment used most frequently should be reported. This scheme does not include various types of sport-specific adaptive equipment (eg, sportspecific prosthesis, mono ski, ice hockey sledge). However, these should be taken into account for research groups wishing to do detailed sport-specific injury and illness risk analyses. Finally, in athletes with vision impairment, the athlete's guide may also be implicated in the causation of the injury and in these instances, 


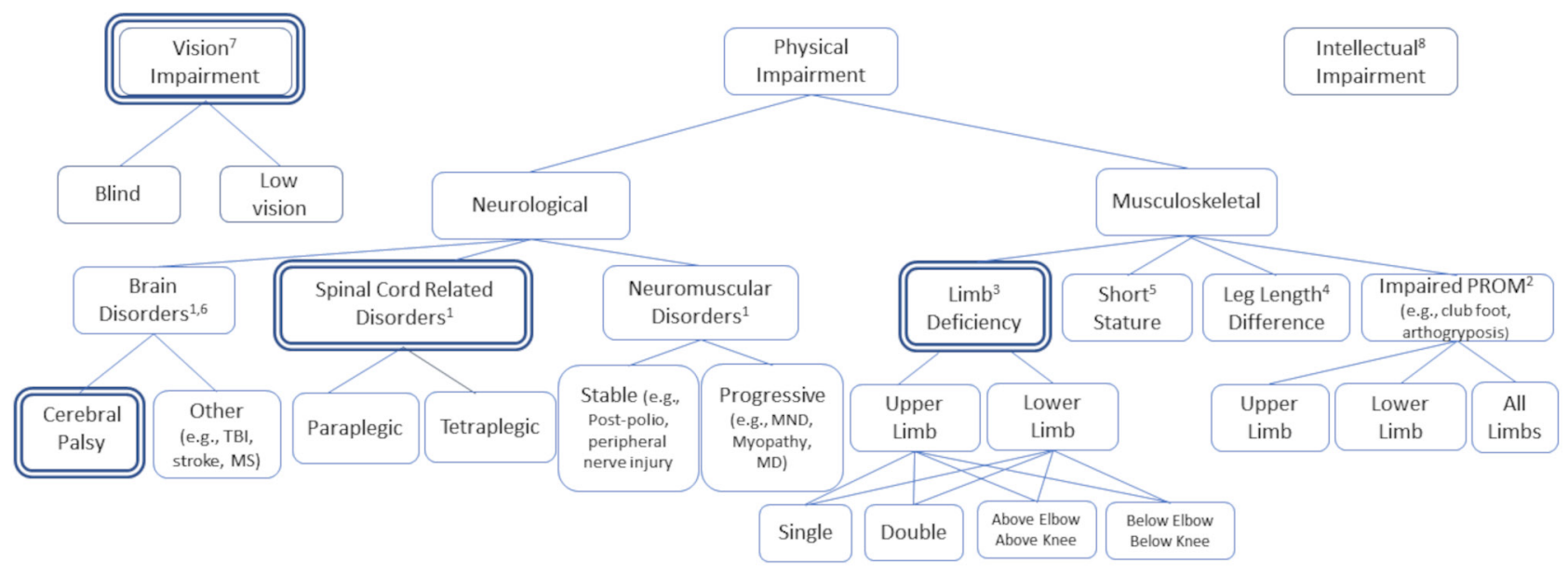

$\mathrm{TBI}=$ traumatic brain injury MS=multiple sclerosis $\mathrm{MND}=$ motor neuron disease $\mathrm{MD}=$ muscular dystrophy PROM=passive range of movement

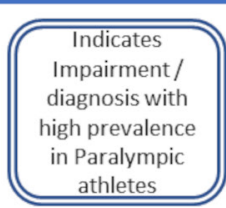

athletes
IPC Eligible Impairments-Classification

1. Impaired muscle power

2. Impaired PROM

3. Limb deficiency

6. Hypertonia, Ataxia, Athetosis

4. Leg length difference 5. Short stature

Figure 1 Schematic representation of suggested diagnostic categorisation and relation to International Paralympic Committee eligible impairments, for Para sport illness and injury surveillance and monitoring programmes. ${ }^{46} \mathrm{It}$ is recommended that at the very minimum, the large diagnostic or impairment groups as indicated in the double outlined boxes, should be recorded.

this should be recorded. The recommended categories represented in both figures 1 and 2 are also contained in the example of an injury and illness report from, located in online supplemental appendix 2 .

\section{Defining and classifying health problems in the context of Para sport \\ Terminology for health problems}

Clarsen et al define an athletic health problem as 'any condition that reduces an athlete's normal state of full health, irrespective of its consequences for the athlete's sports participation or performance or whether the athlete sought medical attention'. ${ }^{28}$ In contrast, defining 'health' for the Para athlete is more complex. Para athletes constitute a heterogeneous population of people with diverse impairments. They do not conform to the WHO definition of health as 'a state of complete physical, mental and social well-being'. ${ }^{29}$ A Para athlete by definition, and by the requirement for participation by minimal eligibility criteria, will have an altered baseline state of 'health'. Thus, an athletic health problem should be recorded when an athlete moves from any state of health, to a 'less-healthy' state. ${ }^{30}$

In the Para athlete, the impairment per se may have associated comorbidities that present in the sporting environment but are not a direct consequence of sport participation itself. While this remains valuable information for healthcare planning, it needs to be considered a confounder in terms of attribution from an epidemiological perspective. The nature of the Para athlete's impairment may also result in a change in the baseline state of health over time, which might result in different levels of risk for injury or illness (see table 1 for examples of confounders). For these reasons, the consensus group strongly recommends the use of the pre-participation evaluation (PPE), periodic health evaluation and the collection of health data in the form of longitudinal studies.

\section{Defining injury and illness}

We concur with the IOC consensus statement's definitions of injury and illness, but definitions require consideration of

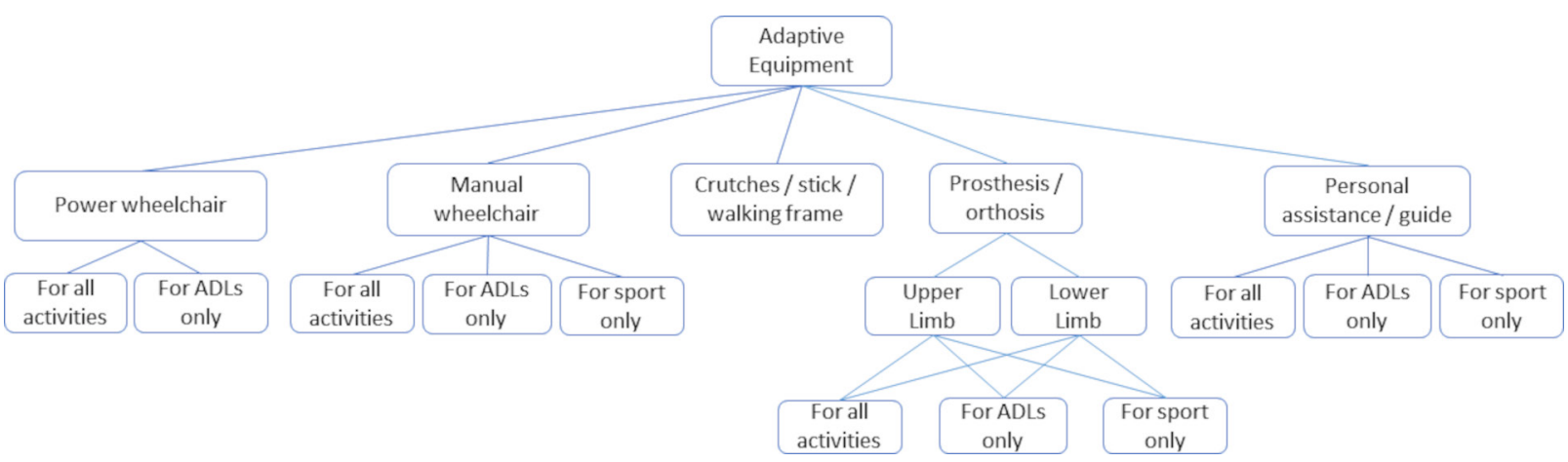

Figure 2 Schematic representation of suggested mobility aid categorisation for Para sport illness and injury surveillance. ADLs, activities of daily living. 
Table 1 Examples of comorbidities associated with certain diagnoses

\begin{tabular}{|c|c|c|}
\hline Diagnosis & Associated comorbidity & Comment \\
\hline Spinal cord injury—wheelchair basketball & $\begin{array}{l}\text { Urinary tract infection associated with neuropathic } \\
\text { bladder }\end{array}$ & Not necessarily sport related \\
\hline $\begin{array}{l}\text { Neuromuscular disorder/muscular dystrophy_-shooting Para } \\
\text { sport }\end{array}$ & Decreasing muscle strength and/or cardiac function & $\begin{array}{l}\text { Decreasing baseline of health over time and cardiac } \\
\text { risk }\end{array}$ \\
\hline Bilateral above knee amputee-handcycling & $\begin{array}{l}\text { Phantom limb pain-athlete uses regular endurance } \\
\text { exercise as a form of pain management }\end{array}$ & $\begin{array}{l}\text { Increased risk of shoulder pain deemed necessary by } \\
\text { the athlete to manage mental health }\end{array}$ \\
\hline $\begin{array}{l}\text { Vision impairment-Para swimming (eg, pseudoxanthoma } \\
\text { elasticum, Stickler syndrome) }\end{array}$ & $\begin{array}{l}\text { Collagen disorder causing sight loss but also affects soft } \\
\text { tissue }\end{array}$ & Increased risk of injury and impaired healing of tissues \\
\hline
\end{tabular}

whether this relates to the existing impairment in a sporting or non-sporting context, as outlined below.

\section{Relationship to sports activity}

We concur with the IOC consensus statement that health problems may result either directly, indirectly, or not at all related to participation in sport. Examples within a Para sport context are shown in table 2.

\section{Mode of onset \\ Mode of onset: injury and illness}

It is important to note that several studies in Para sports have focused on reporting acute injuries at short competitions (3-23 days), while there remains a lack of longitudinal studies that could allow a better understanding of the epidemiology of gradual onset injuries, and the occurrences of illnesses over time. ${ }^{12}$

\section{Classifying mode of onset}

We concur with the IOC consensus statement that data collectors should consider whether a health problem results from a clear acute mechanism, clear repetitive mechanism or a mix of both elements. We have included Para specific examples in online supplemental appendix 3 table $\mathrm{A}$.

\section{Classifying the mechanism of injury}

A similar classification system to the IOC consensus statement is applicable, with the subdivision of contact into fixed objects and moving objects, as in the tennis translation of the IOC consensus statement. ${ }^{17}$ This classification is relevant to various Para sport settings (table 3).

Multiple events, subsequent, recurrent and/or exacerbation of health problems in Para sports epidemiology

The IOC consensus statement emphasises that in sports injury and illness epidemiology, there is a relatively high likelihood that an athlete will experience more than one health problem over a study period. ${ }^{16}$ Figure 3 of the IOC consensus statement depicts a classification tree for subsequent health problems (adapted from Hamilton $e \mathrm{al}^{31}$ ) that is particularly useful in the categorisation of these subsequent injuries/illnesses and exacerbations in sport. In Para sports injury and illness epidemiology, this categorisation is especially relevant. This is because Para athletes experience a higher number of injuries and illness per athlete and due to their health condition also can have a higher number of subsequent injuries, exacerbations, and recurrences of illness and injury. ${ }^{12} 32$ Therefore, in Para sports injury and illness epidemiology, the following should be recorded for any subsequent injuries: whether it is (1) subsequent recurrent (ie, same injury type as index injury, eg, a recurrent rotator cuff tear); (2) subsequent local injury affecting the same location as the index injury but other tissues (eg, shoulder, but acromioclavicular joint instead of the rotator cuff) or (3) subsequent but affecting other location to the index injury. Recurrent injuries are exacerbations if the index injury is not fully healed.

Similarly, for subsequent illnesses it should be recorded if the subsequent illnesses are (1) subsequent recurrent (ie, same diagnosis as index illness, eg, recurrent urinary tract infection); (2) subsequent local affecting the same system (eg, urogenital) but another diagnosis (eg, catheter site infection or cystitis) or (3) subsequent but other systems. Recurrent illnesses are exacerbations if the index illness has not fully recovered. Examples of subsequent health problems in Para sports injury and illness epidemiology can be found in table 4 .

\section{Classifying sports injury and illness diagnoses}

We recommend following the IOC consensus statement to classify injury and illness diagnoses. The diagnoses in the IOC consensus statement are based on the Orchard Sports Injury and Illness Classification System (OSIICS), the Sport Medicine Diagnostic Coding System (SMDSC) and the International Classification of Disease

Table 2 Relationship to sports activity within Para context

\begin{tabular}{|c|c|}
\hline Health problems may result & Para translation \\
\hline $\begin{array}{l}\text { 1. Directly from participation in competition or training in the fundamental skills } \\
\text { of a sport (eg, players colliding in a match, a gradual onset injury from repetitive } \\
\text { training or transmission of a skin infection from contact with another player) }\end{array}$ & $\begin{array}{l}\text { A vision impaired athlete sustains a lower limb fracture in alpine skiing. } \\
\text { An amputee snowboarder develops a skin infection in the residual limb. } \\
\text { A football 5-a-side player sustains a concussion through a collision with another player. }\end{array}$ \\
\hline $\begin{array}{l}\text { 2. Indirectly from participation in activities that relate to competition or training } \\
\text { in a sport, but not during competition or a training session (eg, slipping, falling } \\
\text { and sustaining an injury when in the Paralympic village, developing an illness } \\
\text { following international travel to a competition or an illness deemed to be related } \\
\text { to an increased training load over a few weeks) }\end{array}$ & $\begin{array}{l}\text { A vision impaired athlete falls and sustains a laceration due to an unfamiliar environment. } \\
\text { Para athlete with spinal cord injury develops a urinary tract infection after long-haul travel. }\end{array}$ \\
\hline $\begin{array}{l}\text { 3. From activities that are not at all related to participation in sport } \\
\text { and occur in the absence of participation during competition or training in the } \\
\text { fundamental skills of a sport (eg, car crash, sudden cardiac arrest at home) }\end{array}$ & $\begin{array}{l}\text { An athlete with cerebral palsy sustains an injury as a result of a seizure triggered by } \\
\text { flickering lights in a shopping mall. } \\
\text { An athlete with spinal cord injury experiences autonomic dysreflexia due to a urinary tract } \\
\text { infection. }\end{array}$ \\
\hline
\end{tabular}


Table 3 Examples: classification of contact as a mechanism for sudden-onset injury (adapted from Verhagen et al ${ }^{17}$ )

\begin{tabular}{|c|c|c|c|}
\hline Injury & Type of contact & & Para translation \\
\hline Non-contact & None & No evidence of disruption or perturbation & A wheelchair sprinter experiences sudden pain in the shoulder during a race. \\
\hline \multirow[t]{3}{*}{ Contact } & Indirect & With another athlete & $\begin{array}{l}\text { An outfield football 5-a-side player (football played by athletes with vision } \\
\text { impairment who have very low visual acuity and/or no light perception) trips over } \\
\text { another player's leg, causing a lateral ankle ligament sprain. }\end{array}$ \\
\hline & Indirect & With a fixed object & $\begin{array}{l}\text { A Para snowboarder loses control and accidently hits a gate which causes him to } \\
\text { tumble and sprain his wrist. }\end{array}$ \\
\hline & Indirect & With a moving object & $\begin{array}{l}\text { A wheelchair basketball player is hit on the head by a ball, causing her to lose } \\
\text { balance and fall, spraining her wrist. }\end{array}$ \\
\hline \multirow[t]{3}{*}{ Contact } & Direct & With another athlete & $\begin{array}{l}\text { A vision impaired player sustains a concussion from a collision with another } \\
\text { player in a football } 5 \text {-a-side game. }\end{array}$ \\
\hline & Direct & With a fixed object & A Para ice hockey player is checked into the boards and dislocates his shoulder. \\
\hline & Direct & With a moving object & $\begin{array}{l}\text { A sitting volleyball player is hit on the head by a spiked ball and sustains a } \\
\text { concussion. }\end{array}$ \\
\hline
\end{tabular}

(ICD)..$^{33}$ These coding systems were recently updated to include some common Para athlete specific codes, for example, common amputation sites. For athletes with amputation or congenital limb anomalies, residual limb injuries can be recorded according to their primary anatomical area, for example, upper or lower limb. Researchers can choose to be more specific and add the specific amputation level, for example, above the knee (transfemoral) or the elbow (transhumeral). An expanded list of all amputations is shown in online supplemental appendix 3 table B.

It is noteworthy that some tissue types and pathology related to Para athletes' diagnoses are not included as Para athlete specific conditions in the existing systems (OSIICS and SMDCS). ${ }^{33}$ For example, a pressure ulcer is a frequent and often severe tissue injury that affects athletes with reduced sensation. Among athletes with neurological impairment, joint contractures may be present as well as other nervous system-related injuries. ${ }^{123536}$ Therefore, we recommend researchers to identify and record the impairment-specific tissue injuries and pathology that may be present in the Para athlete population. See examples in table 5.

It is also possible to use diagnostic codes from the ICD-10 and ICD-11 in instances where diagnoses cannot be found. ${ }^{12} 36$

Illness: categories for organ system and aetiology

Paralympic athletes have significantly higher rates of illness than their Olympic counterparts with unique medical conditions related to their type of diagnosis, such as autonomic dysreflexia, pressure injuries, neurogenic bladder, premature osteoporosis and neuropathic pain. ${ }^{3}$ Para athletes also have more skin and subcutaneous lesions related to insensate skin and residual limb/prosthesis interface pathology. ${ }^{243738}$ For example, non-traumatic skin lesions on the residual limb in amputees, or sunburn/frostbite on insensate skin, need to be categorised separately from other dermatological conditions, and a hypertensive crisis due to autonomic dysreflexia should be recorded separately from common neurological or cardiovascular conditions listed in ICD-10 and ICD-11.

We recommend adding these specific medical conditions in Para athletes as subcategories in existing categories of organ system/region in the IOC consensus statement. For example, insensate skin and/or residual limb can be included as a subcategory of the dermatological system. For cases of autonomic dysreflexia in spinal cord injury or seizure in brain injury, a subcategory of the central nervous system, peripheral nervous system, and autonomic nervous system can be added to the nervous system. We recommend adding a 'comorbidity of existing diagnosis' to the categories for aetiology of illness for these unique medical conditions in Para athletes as in table 6.

\section{Severity of health problems}

Time loss from training and competition

We agree with the IOC consensus statement that investigators should consider the strengths and limitations of different

Table 4 Examples of subsequent health problems in Para sports injury and illness epidemiology

\begin{tabular}{|c|c|c|c|c|}
\hline \multirow[t]{3}{*}{ Index injury } & \multicolumn{4}{|c|}{ Subsequent injury } \\
\hline & \multicolumn{2}{|c|}{ Recurrent injury } & \multirow{2}{*}{$\begin{array}{l}\text { Local injury } \\
\text { (same location but different tissue } \\
\text { type) }\end{array}$} & \multirow{2}{*}{$\begin{array}{l}\text { New injury (different location } \\
\text { and tissue type) }\end{array}$} \\
\hline & $\begin{array}{l}\text { Re-injury } \\
\text { (same site and same type as } \\
\text { the index injury, index injury } \\
\text { was healed/fully recovered) }\end{array}$ & $\begin{array}{l}\text { Exacerbation } \\
\text { (same site and same type as the } \\
\text { index injury, index injury not yet } \\
\text { healed/fully recovered) }\end{array}$ & & \\
\hline $\begin{array}{l}\text { Rotator cuff tendinopathy in an } \\
\text { athlete with spinal cord injury } \\
\text { using a wheelchair for racing }\end{array}$ & $\begin{array}{l}\text { Acute rotator cuff tear in this } \\
\text { athlete }\end{array}$ & Recurrent rotator cuff tear & $\begin{array}{l}\text { Acromioclavicular joint sprain in this } \\
\text { athlete }\end{array}$ & $\begin{array}{l}\text { Acute wrist sprain in this } \\
\text { athlete }\end{array}$ \\
\hline \multirow[t]{3}{*}{ Index illness } & \multicolumn{4}{|c|}{ Subsequent illness } \\
\hline & \multicolumn{2}{|c|}{ Recurrent illness } & \multirow{2}{*}{$\begin{array}{l}\text { Local illness } \\
\text { (same organ system but different } \\
\text { illness type) }\end{array}$} & \multirow{2}{*}{$\begin{array}{l}\text { New illness (different organ } \\
\text { system and illness type) }\end{array}$} \\
\hline & $\begin{array}{l}\text { Repeated illness } \\
\text { (same organ system and same } \\
\text { type as the index illness, index } \\
\text { illness fully recovered) }\end{array}$ & $\begin{array}{l}\text { Exacerbation of illness } \\
\text { (same organ system and same type } \\
\text { as the index illness, index illness } \\
\text { not yet fully recovered) }\end{array}$ & & \\
\hline $\begin{array}{l}\text { Neurogenic bladder in an athlete } \\
\text { with spinal cord injury }\end{array}$ & $\begin{array}{l}\text { Urinary tract infection in this } \\
\text { athlete }\end{array}$ & Pyelonephritis & $\begin{array}{l}\text { Skin infection at the catheter site in } \\
\text { this athlete }\end{array}$ & $\begin{array}{l}\text { Upper respiratory tract } \\
\text { infection in this athlete }\end{array}$ \\
\hline
\end{tabular}


Table 5 Examples of additional categories of tissue and pathology types for injuries in Para athletes

\begin{tabular}{ll}
\hline Tissue & Pathology \\
\hline Nervous system & $\begin{array}{l}\text { Hypertonia } \\
\text { Central neurological pain } \\
\text { Phantom pain }\end{array}$ \\
Ligament/joint capsule & Contracture \\
Superficial tissue/skin & Pressure ulcer \\
\hline
\end{tabular}

approaches and the objectives of their study or surveillance programme, when deciding which severity measures to use. Similarly, we agree with the IOC consensus statement that time loss is the most commonly used criterium for assessment of severity. Online supplemental appendix 3 table $\mathrm{C}$ gives practical examples of how to calculate time loss in the Para athlete setting. Using 'time loss' for Para athletes has the same limitations as for able-bodied athletes, yet, there are additional considerations and complexities. For example, athletes who use a wheelchair for their sport and sustain an injury to one functional arm may lose independence in daily life, making the impact of such an injury of greater severity than the number of days lost from sport or training alone.

The decision to monitor additional severity parameters, such as non-sport related functional limitations and pain, will depend on the aim of the research. For Para athletes with specific underlying diagnoses, there are outcome measures used in disability research that can be relevant, specifically for evaluation of the impact of the individual's impairment on their activities of daily living. One such example is the Wheelchair Users Pain Shoulder Index (WUSPI). ${ }^{39}$ The WUSPI is a simple and effective selfreported questionnaire for rapid assessment of the functional impact of shoulder pain in wheelchair users. Another example is the Sports-related Injury and Illness in Paralympic Sport Study (SRIIPSS) that included self-reported injuries, illnesses, impairment related symptoms and other health parameters such as pain, anxiety, sleep and use of medications.

\section{Para athlete reported symptoms and consequences}

Existing tools for able-bodied athletes that allow self-reporting of data (eg, symptom recording and training exposure) require adaptation for the Para sport environment. For example,

Table 6 Examples of medical conditions specific to Para athletes as a result of existing diagnoses

\begin{tabular}{ll}
\hline Diagnosis & Medical problems \\
\hline Spinal cord injury & Pressure ulcers \\
& Autonomic dysreflexia \\
& Urinary tract infection \\
& Premature osteoporosis \\
& Renal calculi \\
& Neuropathic pain \\
& Pulmonary dysfunction \\
& Premature osteoporosis \\
Poliomyelitis & Osteoarthrosis \\
& Nociceptive pain \\
Amputee & Residual limb infection \\
& Phantom limb pain \\
Cerebral palsy/brain injury & Convulsive disorders \\
& Depression \\
& Fatigue \\
\hline
\end{tabular}

This table should be read in conjunction with table 7 of the IOC consensus statement. reporting tools should allow vision impaired athletes and athletes with an intellectual impairment to respond and provide their data on the system. Specific accessibility considerations are described in detail under the section 'Data collection methods'. Also, some Para athletes with more severe impairments who have higher needs with respect to daily activities might require the assistance of another person to respond and provide data. It should also be possible to include other health symptoms and consequences such as pain, sleep, well-being, medications as well as functional and mental limitations if necessary. An example of one such electronic system is the SRIIPSS eHealth application, which has been specifically developed for all types of Para athletes. $^{13}$

\section{Recording the severity of health problems based on clinical} assessment

As the athlete's health can fluctuate due to underlying medical conditions and changes in the impairment, we recommend that sufficient baseline data at the time of the PPE are gathered and recorded, to allow a point of reference for the assessment of subsequent health problems. As access to healthcare can vary considerably for Para athletes, the PPE is rarely conducted in some countries. Therefore, it is a challenge to report the subsequent severity of the athletes' current clinical assessment, as there is no initial benchmark. If baseline health state is unknown prior to the recorded injury or illness, this should be indicated in the injury report. If possible, patient interviews may help identify changes in health state in athletes who do not have well documented health histories. Furthermore, the advent of telemedicine and eHealth approaches might mitigate this particular challenge and may become increasingly popular as an assessment and data collection tool.

\section{Other severity measures}

It is important for researchers to consider that certain patientreported outcome measures for able-bodied athletes cannot be readily used for Para athletes without specific development and testing. One such example is the sports concussion instrument, Sport Concussion Assessment Tool, which cannot be adopted for Para athletes without further development. ${ }^{40}$ In these instances, we recommend the the adaptation and validation existing sportsrelated outcome measures for Para athletes.

\section{Capturing and reporting athlete exposure}

Apart from the differences in types of sport for Para athletes compared with able-bodied athletes, the fundamental principles of capturing and reporting exposure, as described in the IOC consensus statement, remains the same. As Para sport types are varied and take place both in the winter and summer sport settings, we recommend exposure measures to be sport-specific (eg, total athlete distance covered, athlete time in competition, number of athlete bouts/fights, athlete days)(online supplemental appendix 3 table D). The context of recording training exposure in Para sport should be sport-specific and athlete-specific and consider categories of general strength and conditioning, and injury-specific rehabilitation targeting safe return to sport.

\section{Expressing risk}

While we agree with the recommendation of the IOC consensus statement regarding point prevalence and period prevalence, understanding of these requires a consideration of the complexity of Para sport taking into account the high prevalence of pre-existing medical conditions chronic pain, comorbidities 
and prolonged use of adaptive equipment. ${ }^{3}$ Thus, injury and illness incidence rates may underestimate the true burden given the high prevalence of pre-existing repetitive gradual onset injuries and medical conditions. Also, when collecting data in multisport events, and when exposure data are incomparable between sports, ${ }^{253641}$ we recommend expressing incidence as the number of new cases/number of athletes or athlete days. Sport-specific incidence rates may be more optimally expressed by number of health problems/1000 matches (eg, badminton, boccia, football, goalball, judo, sitting volleyball, table tennis, wheelchair basketball, wheelchair fencing, wheelchair tennis) or number of injuries/1000 competitions or events (eg, archery, athletics, canoe, cycling, equestrian, power lifting, rowing, shooting, swimming, taekwondo, dance).

\section{Burden of health problems}

Time loss-based severity measures also under-represent gradual onset injuries and illnesses, which are particularly prevalent in the Para sport population. ${ }^{12} 1436$ In this context, we recommend the use of mean severity scores (measured as arbitrary units) by the Oslo Sports Trauma Research Center-Health questionnaire, instead of measuring only time loss from sports participation. ${ }^{42}$ This questionnaire has been used in Para sport health monitoring, with the exception of vision impaired athletes. ${ }^{14} \mathrm{New}$ vs pre-existing morbidity must be clearly delineated in the Para sport population where exacerbations are prevalent.

\section{Data collection methods}

In Para sport, there are different factors relating to the Para athletes' impairment that should be considered when data are collected. As such, there is a need for flexibility regarding data collection methods in order to adapt to specific context and population differences that will improve validity and reliability. $^{21316}$ Various considerations in this regard are shown in table 7 . We recommend that researchers think carefully about these, and other potential considerations that may be present with their own, specific research contexts.

For prospective data collection over time and throughout a season, methods adapted to Para athletes based on self-reports have successfully been developed and evaluated within the SRIIPSS and other longitudinal surveillance projects. ${ }^{13} 14 \quad 43$ An example of an injury and illness report form in Para sport, adapted from the IOC consensus statement and SRIIPSS, is provided in online supplemental appendix $2 .^{12} 13164445$ eHealth based self-report data collection may be especially beneficial, as it can empower health efficiency and autonomy for persons with an impairment due to more accessible opportunities for communicating health parameters. ${ }^{44}$ Digital data collection of other health parameters, such as heart rate and energy expenditure, could also be a feasible method among Para athletes due to a large variation in physiology and training.

\section{Accessibility considerations}

There are guidelines and regulations in various countries that may facilitate accessibility for web interfaces and mobile applications. In the USA, for example, researchers may collaborate with experts of the Americans with Disabilities Act (ADA), to ensure their surveillance tools meet ADA guidelines. However, to encourage uniformity and ensure accessibility and validity for all data collection methods for Para athletes, we recommended following the Web Content Accessibility Guidelines. To ensure accessibility for athletes with vision impairment, it is recommended to avoid using paper and pen for blind athletes,
Table 7 Para sport specific additions concerning data collection methods to the IOC consensus statement

\begin{tabular}{|c|c|}
\hline Data collection concerns & Considerations \\
\hline $\begin{array}{l}\text { Data collected during } \\
\text { competitions }\end{array}$ & $\begin{array}{l}\text { Para athletes often do not have access to a } \\
\text { team physician (and physician experience can } \\
\text { vary greatly), consider whether data can be } \\
\text { reported by other medical staff, coaches or } \\
\text { athletes themselves. } \\
\text { Consider how diagnosis is made (eg, with } \\
\text { objective methods such as imaging). } \\
\text { Consider collecting data in several languages. }\end{array}$ \\
\hline $\begin{array}{l}\text { Data collected during training } \\
\text { seasons }\end{array}$ & $\begin{array}{l}\text { A global injury/illness reporting app/software } \\
\text { that allows each Para sport to record their } \\
\text { data are preferable. } \\
\text { Prospective data collection of self-reports can } \\
\text { be recommended where athletes do not have } \\
\text { access to medical staff. }{ }^{32}\end{array}$ \\
\hline \multicolumn{2}{|l|}{$\begin{array}{l}\text { Accessibility concerns of } \\
\text { impairment groups within the } \\
\text { Paralympic movement }\end{array}$} \\
\hline $\begin{array}{l}\text { Athletes with vision } \\
\text { impairment }\end{array}$ & $\begin{array}{l}\text { Adapt electronic reporting to different } \\
\text { devices and speech synthesisers. } \\
\text { Avoid pen and paper. } \\
\text { Use large text and consider braille. } \\
\text { Avoid pictures and scales. }\end{array}$ \\
\hline $\begin{array}{l}\text { Athletes with intellectual } \\
\text { impairment }\end{array}$ & $\begin{array}{l}\text { Use easy and understandable terminology. } \\
\text { Provide free text options. } \\
\text { Provide visual cues. }\end{array}$ \\
\hline $\begin{array}{l}\text { Athletes with (severe) physical } \\
\text { impairment }\end{array}$ & $\begin{array}{l}\text { Avoid pen and paper. } \\
\text { Adapt electronic reporting to different } \\
\text { devices and assistive writing technology. }\end{array}$ \\
\hline
\end{tabular}

and scales and pictures must be avoided. These methods can, however, be considered for partially sighted athletes if large text is used. eHealth based data collection can be used advantageously in this population, but it is important to ensure that the method is compatible with multiple devices, speech synthesisers and braille. ${ }^{43} 44$

For athletes with intellectual impairment, it is important to use data collection methods containing easily understandable terminology and to allow visual cues and free text answers. For some athletes with more severe physical impairments, such as tetraplegia, it is recommended to avoid pen and paper and adapt eHealth based options with assistive technology for writing. ${ }^{44}$ It is important to consider the provision of support personnel to assist with data collection among some athletes with impairment. ${ }^{43}$

Finally, the IOC consensus statement highlights the importance of ethics in research and data security. In the context of Para sport, we urge researchers to carefully consider and ensure the protection of dignity and rights of participants, especially as some Para athletes may be considered persons at risk or vulnerable, due to their specific impairment.

\section{CONCLUSION}

Accurate and standardised use of specific definitions, methods and parameters to collect and report epidemiological data in the complex Para sport environment is an important step in the prevention of injury and illness and protection of health of the Para athlete. In response to the recent IOC consensus statement on methods for recording and reporting of epidemiological data on injury and illness in sport, experts in the field of Para sports medicine have translated this consensus statement into a Para 
sport context. This Para sport translation offers more detailed impairment and sport specific information that will allow researchers in this field to better record and report both injuries and illness.

\section{Author affiliations}

'Institute of Sport and Exercise Medicine (ISEM), Division of Orthopaedic Surgery, Department of Surgical Sciences, Stellenbosch University Faculty of Medicine and Health Sciences, Cape Town, South Africa

${ }^{2}$ International Olympic Committee Research Centre, South Africa

IPC Medical Committee, Bonn, Germany

${ }^{4}$ Sports Performance Research Institute New Zealand (SPRINZ), Auckland University of Technology, Auckland, New Zealand

Department of Physical Medicine and Rehabilitation, Spaulding Rehabilitation Hospital/Harvard Medical School, Boston, Massachusetts, USA

${ }^{6}$ Sport Injury Prevention Research Centre, Faculty of Kinesiology and Cumming

School of Medicine, University of Calgary, Calgary, Alberta, Canada

${ }^{7}$ International Olympic Committee Research Center, Calgary, Alberta, Canada

${ }^{8}$ Rehabilitation Medicine Research Group, Department of Health Sciences, Lund University, Lund, Sweden

${ }^{9}$ Department of Rehabilitation Medicine, Yonsei University Wonju College of Medicine, Seodaemun-gu, Korea (the Republic of)

${ }^{10}$ International Olympic Committee Research Center, Seoul, Korea (the Republic of)

${ }^{11}$ Yonsei Institute of Sports Science and Exercise Medicine, Seoul, Korea (the Republic of)

${ }^{12}$ Department of Family Medicine, University of Ottawa, Ottawa, Ontario, Canada

${ }^{13}$ Department of Rehabilitation Medicine, Skåne University Hospital, Lund, Sweden

${ }^{14}$ English Institute of Sport, Manchester, UK

${ }^{15}$ British Paralympic Association, London, UK

${ }^{16}$ Section Sports Medicine, Faculty of Health Sciences, University of Pretoria, Pretoria, South Africa

${ }^{17}$ Amsterdam Collaboration on Health \& Safety in Sports (ACHSS), AMC/VUmC IOC Research Center of Excellence, Amsterdam, The Netherlands

${ }^{18}$ Medical Department, Royal Netherlands Lawn Tennis Association (KNLTB), Amstelveen, The Netherlands

${ }^{19}$ Sport, Exercise Medicine and Lifestyle Institute (SEMLI), University of Pretoria, Faculty of Health Sciences, Pretoria, South Africa

${ }^{20}$ Oslo Sports Trauma Research Center, Norwegian School of Sports Sciences, Oslo, Norway

${ }^{21}$ International Olympic Committee Research Center, Norway

${ }^{22}$ The Norwegian Olympic Training Center (Olympiatoppen), Oslo, Norway

${ }^{23}$ Former Medical \& Scientific Director International Paralympic Committee, Bonn,

Germany

${ }^{24}$ Immune-Oncological Centre, Cologne, Germany

${ }^{25}$ Centre for Sport and Exercise Science and Medicine (SESAME), School of Sport and Service Management, University of Brighton, Brighton, UK

${ }^{26}$ School of Sport, Exercise and Health Sciences, Loughborough University, Loughborough, UK

${ }^{27}$ Fortius Clinic, London, UK

TwitterWayne Derman @wderman, Cheri Blauwet@CABlauwet, Carolyn A Emery @CarolynAEmery, Kristina Fagher @KristinaFagher, Babette M Pluim @docpluim and NickWebborn@SportswiseUK

Contributors All authors were part of the teleconferences and made substantial contributions. Please refer to the Methods section.

Funding The authors have not declared a specific grant for this research from any funding agency in the public, commercial or not-for-profit sectors.

Competing interests None declared.

Patient consent for publication Not required.

Provenance and peer review Not commissioned; externally peer reviewed.

Supplemental material This content has been supplied by the author(s). It has not been vetted by BMJ Publishing Group Limited (BMJ) and may not have been peer-reviewed. Any opinions or recommendations discussed are solely those of the author(s) and are not endorsed by BMJ. BMJ disclaims all liability and responsibility arising from any reliance placed on the content. Where the content includes any translated material, BMJ does not warrant the accuracy and reliability of the translations (including but not limited to local regulations, clinical guidelines, terminology, drug names and drug dosages), and is not responsible for any error and/or omissions arising from translation and adaptation or otherwise.

\section{ORCID iDs}

Wayne Derman http://orcid.org/0000-0002-8879-177X

Marelise Badenhorst http://orcid.org/0000-0001-8443-9173

Carolyn A Emery http://orcid.org/0000-0002-9499-6691
Kristina Fagher http://orcid.org/0000-0002-9524-7553

lan Stuart Miller http://orcid.org/0000-0002-6085-7407

Babette M Pluim http://orcid.org/0000-0003-0655-8980

Martin Schwellnus http://orcid.org/0000-0003-3647-0429

Kathrin Steffen http://orcid.org/0000-0002-6238-608X

Richard Weiler http://orcid.org/0000-0002-6216-839X

\section{REFERENCES}

1 Fagher K, Lexell J. Sports-Related injuries in athletes with disabilities. Scand J Med Sci Sports 2014;24:e320-31.

2 Weiler R, Van Mechelen W, Fuller C, et al. Sport injuries sustained by athletes with disability: a systematic review. Sports Med 2016;46:1141-53.

3 Janse Van Rensburg DC, Schwellnus M, Derman W, et al. Illness among Paralympic athletes: epidemiology, risk markers, and preventative strategies. Phys Med Rehabil Clin N Am 2018:29:185-203.

4 Webborn N, Van de Vliet P. Paralympic medicine. The Lancet 2012;380:65-71.

5 Soligard T, Steffen K, Palmer-Green D, et al. Sports injuries and illnesses in the Sochi 2014 Olympic winter games. Br J Sports Med 2015;49:441-7.

6 Derman W, Schwellnus MP, Jordaan E, et al. High incidence of injury at the Sochi 2014 winter Paralympic games: a prospective cohort study of 6564 athlete days. Br I Sports Med 2016:50:1069-74.

7 Soligard T, Steffen K, Palmer D, et al. Sports injury and illness incidence in the Rio de Janeiro 2016 Olympic summer games: a prospective study of 11274 athletes from 207 countries. Br J Sports Med 2017;51:1265-71.

8 Derman W, Runciman P, Schwellnus M, et al. High precompetition injury rate dominates the injury profile at the Rio 2016 Summer Paralympic Games: a prospective cohort study of 51198 athlete days. Br J Sports Med 2018;52:24-31.

9 Engebretsen L, Soligard T, Steffen K, et al. Sports injuries and illnesses during the London summer Olympic Games 2012. Br J Sports Med 2013;47:407-14.

10 Derman W, Schwellnus M, Jordaan $\mathrm{E}$, et al. Illness and injury in athletes during the competition period at the London 2012 Paralympic games: development and implementation of a web-based surveillance system (WEB-IISS) for team medical staff. Br J Sports Med 2013;47:420-5.

11 Webborn N, Willick S, Reeser JC. Injuries among disabled athletes during the 2002 winter Paralympic Games. Med Sci Sports Exerc 2006;38:811-5.

12 Fagher K, Dahlström Örjan, Jacobsson J, et al. Prevalence of sports-related injuries and illnesses in Paralympic athletes. PM R 2020;12:271-80.

13 Fagher K, Jacobsson J, Timpka T, et al. The sports-related injuries and illnesses in Paralympic sport study (SRIIPSS): a study protocol for a prospective longitudinal study. BMC Sports Sci Med Rehabil 2016;8:28

14 Hirschmüller A, Fassbender K, Kubosch J. Injury and illness surveillance in elite Paralympians - urgent need for suitable illness prevention strategies in para athletes. Am J Phys Med Rehabil 2020.

15 Tuakli-Wosornu YA, Mashkovskiy E, Ottesen T, et al. Acute and chronic musculoskeletal injury in para sport: a critical review. Phys Med Rehabil Clin N Am 2018:29:205-43.

16 Bahr R, Clarsen B, Derman W, et al. International Olympic Committee consensus statement: methods for recording and reporting of epidemiological data on injury and illness in sport 2020 (including STROBE extension for sport injury and illness surveillance (STROBE-SIIS)). Br I Sports Med 2020:54:372-89.

17 Verhagen E, Clarsen B, Capel-Davies J, et al. Tennis-specific extension of the International Olympic Committee consensus statement: methods for recording and reporting of epidemiological data on injury and illness in sport 2020. Br I Sports Med 2021;55:9-13

18 Murray A, Junge A, Robinson PG, et al. International consensus statement: methods for recording and reporting of epidemiological data on injuries and illnesses in golf. $B r$ J Sports Med 2020:54:1136-41.

19 Webborn N, Blauwet CA, Derman W, et al. Heads up on concussion in para sport. Br J Sports Med 2018:52:1157-8.

20 International Paralympic Committee. International Paralympic Committee style guide, 2017. Available: www.paralympic.org [Accessed 12 Aug 2020].

21 World Health Organization. Towards a common language for functioning, disability and health: ICF - The International Classification of Functioning, Disability and Health, 2002. Available: https://www.who.int/classifications/icf/icfbeginnersquide.pdf?ua=1 [Accessed 8 Jun 2020].

22 World Health Organisation. International classification of functioning, disability and health, 2001. Available: http://www.who.int/classifications/icf/en/

23 Webborn N. "What do you mean, a wheelchair athlete?". Curr Sports Med Rep 2011;10:246-7.

24 Derman W, Schwellnus MP, Jordaan E, et al. Sport, sex and age increase risk of illness at the Rio 2016 summer Paralympic games: a prospective cohort study of 51198 athlete days. Br J Sports Med 2018;52:17-23.

25 Blauwet CA, Cushman D, Emery C, et al. Risk of injuries in Paralympic track and field differs by impairment and event discipline: a prospective cohort study at the London 2012 Paralympic Games. Am J Sports Med 2016:44:1455-62.

26 International Paralympic Committee. IPC athlete classification code rules, policies, and procedures for athlete classification, 2015. Available: www.paralympic.org [Accessed 12 Aug 2020]. 
27 Webborn AD. Fifty years of competitive sport for athletes with disabilities: 1948-1998. Br J Sports Med 1999;33:138.

28 Clarsen B, Bahr R, Myklebust G, et al. Improved reporting of overuse injuries and health problems in sport: an update of the Oslo sport trauma research center questionnaires. Br J Sports Med 2020;54:390-6.

29 World Health Organization. World Health organization constitution, 2016. Available: http://www.who.int/about/mission/en/ [Accessed 14 Sep 2020].

30 Shrier I, Clarsen B, Verhagen E, et al. Improving the accuracy of sports medicine surveillance: when is a subsequent event a new injury? $\mathrm{Br} / \mathrm{Sports}$ Med 2017:51:26-8.

31 Hamilton GM, Meeuwisse WH, Emery CA, et al. Subsequent injury definition, classification, and consequence. Clin I Sport Med 2011;21:508-14.

32 Fagher K, Forsberg A, Jacobsson J, et al. Paralympic athletes' perceptions of their experiences of sports-related injuries, risk factors and preventive possibilities. Eur $J$ Sport Sci 2016;16:1240-9.

33 Orchard JW, Meeuwisse W, Derman W, et al. Sport medicine diagnostic coding system (SMDCS) and the orchard sports injury and illness classification system (OSIICS): revised 2020 consensus versions. Br J Sports Med 2020;54:397-401.

34 World Health Organization. International classification of diseases, 11th revision (ICD-11), 2018. Available: https://www.who.int/classifications/icd/en/ [Accessed 8 Jun 2020].

35 Webborn N, Van de Vliet P. Paralympic medicine. Lancet 2012;380:65-71.

36 Fagher K, Ö D, Jacobsson J. Injuries and illnesses in Swedish Paralympic athletes-A 52-week prospective study of incidence and risk factors. Scand J Med Sci Sports (Published Online First: 17 May 2020).
37 Soligard T, Palmer D, Steffen K, et al. Sports injury and illness incidence in the PyeongChang 2018 Olympic winter games: a prospective study of 2914 athletes from 92 countries. Br J Sports Med 2019;53:1085-92.

38 Derman W, Runciman $\mathrm{P}$, Jordaan $\mathrm{E}$, et al. Incidence rate and burden of illness at the Pyeongchang 2018 Paralympic winter games. Br J Sports Med 2019;53:1099-104.

39 Curtis KA, Roach KE, Applegate EB, et al. Development of the wheelchair user's shoulder pain index (WUSPI). Paraplegia 1995:33:290-3.

40 Weiler R, van Mechelen W, Fuller C, et al. Do neurocognitive SCAT3 baseline test scores differ between footballers (soccer) living with and without disability? A crosssectional study. Clin I Sport Med 2018;28:43-50.

41 Hollander K, Kluge S, Glöer F, et al. Epidemiology of injuries during the wheelchair Basketball world Championships 2018: a prospective cohort study. Scand J Med Sci Sports 2020;30:199-207.

42 Clarsen B, Bahr R, Myklebust G, et al. Improved reporting of overuse injuries and health problems in sport: an update of the Oslo sport trauma research center questionnaires. Br J Sports Med 2020:54:390-6.

43 Fagher K, Hassan Ahmed O, Pernheim N, et al. Prevalence of sports-related injuries in Paralympic judo: an exploratory study. J Sci Med Sport 2019:22:902-6.

44 Fagher K, Jacobsson J, Dahlström Örjan, et al. An eHealth application of self-reported sports-related injuries and illnesses in Paralympic sport: pilot feasibility and usability study. JMIR Hum Factors 2017;4:e30

45 Fagher K. Sports-Related injuries and illnesses in Paralympic athletes 2019.

46 International Paralympic Committee. International standard for eligible impairments, 2016. Available: www.paralympic.org [Accessed 12 Aug 2020]. 